\title{
Las catástrofes naturales como instrumento de observación social: el caso del terremoto de Lima en 1746
}

Pablo E. Pérez-Mallaína

Universidad de Sevilla

El presente trabajo se ocupa de estudiar el gran terremoto que destruyó Lima y asoló su puerto de El Callao en 1746. Fue el movimiento sísmico más destructivo que soportó la capital del Perú durante la época colonial y originó una profunda y dramática crisis. El temblor no sólo produjo un gran número de víctimas y considerables daños materiales, sino que también provocó numerosas confrontaciones entre los vecinos. Nuestro propósito es utilizar la catástrofe natural como un instrumento de observación social, lo cual nos permitirá vislumbrar las peculiaridades, los prejuicios, los intereses y las creencias de una gran ciudad de la América española durante el siglo XVIII.

PALABRAS CLAVES: Lima; terremoto, sociedad urbana, siglo XVIII.

This essay is about the events following the earthquake that struck Lima and its port of Callao in 1746. This earthquake was the most serious ever suffered by the capital of Peru during colonial times and originated a deep and dramatic crisis in the city. It caused not only a great number of victims and widespread damage, but also numerous confrontations amongst neighbours. We will used the catastrophe as an observation instrument, and therefore, the study of these events allows us to glimpse a clearer view of the peculiarities, prejudices, interests and beliefs of a large city in Hispanic America during the 18th century.

KEYWORDS: Lima; urban society; earthquake; $18^{\text {th }}$ century.

El 28 de octubre de 1746 se produjo un violento seísmo seguido de un maremoto, que provocó considerables destrozos en la capital del virreinato del Perú y borró del mapa su puerto de El Callao. Los contemporáneos lo calificaron como el más destructivo sufrido por Lima hasta ese momento, sólo comparable a la otra "ruina general"; es decir, el gran terremoto que 59 años antes, exactamente el 20 de octubre de 1687, asoló la ciudad. Desde entonces y hasta ahora, el hecho de que esas dos grandes catástrofes coincidiesen en el mismo mes ha convertido al mes de octubre en un periodo en el que muchos limeños acostumbran todavía a pedir perdón por sus 
pecados, sacando en procesión al Cristo de los Milagros, considerado como el principal protector contra la furia de los elementos.

Aunque resulta difícil de dilucidar si hubo mayores daños materiales en 1687 que en 1746, es indudable que en esta última ocasión se produjeron muchas más víctimas mortales. En 1687 perecieron en la capital unas 500 personas, mientras que en 1746 la lista oficial de víctimas se elevó a 1.141, pero eso fue sólo en Lima, pues en El Callao, que por entonces tenía unos 5.000 habitantes, no se contaron los muertos, sino los supervivientes, que sólo fueron alrededor de 300 . Ambas catástrofes se cobraron las vidas de entre 5.000 a 6.000 personas, que sobre una población total de aproximadamente 65.000 habitantes, supone un porcentaje de víctimas de entre el 8 y el $9 \%$, por lo que constituye un desastre de enormes proporciones. ${ }^{1}$

Los daños materiales fueron igualmente graves. Hubo que construir de nuevo las fortificaciones y población de El Callao, al igual que los dos edificios más significativos de la capital: el palacio virreinal y la catedral. Los principales hospitales, conventos y templos sufrieron derrumbes y grandes destrozos, únicamente permaneció ilesa la iglesia de San Francisco y la Santo Domingo sufrió daños menores. En fin, algunas crónicas exageradas llegaron a decir que de las 3.000 casas de Lima sólo permanecieron en pie poco más de 20 .

Como puede comprenderse, la reconstrucción supuso invertir grandes cantidades de dinero y se prolongó a lo largo de muchas décadas. Aunque el palacio virreinal estuvo reparado en unos pocos años, ${ }^{2}$ hasta 1758 no se terminaron las obras de restauración de la Catedral. Las fortificaciones del puerto se completaron en una primera fase en 1761, pero el levantamiento de los cuarteles y equipamientos se prolongó por mucho más tiempo. En cuanto a las numerosas iglesias y edificios religiosos arrumbados, en algunos casos, como el del gran convento de la Encarnación, no se completó su rehabilitación hasta la última década del siglo XVIII.

En suma, nos encontramos ante un suceso de extraordinarias repercusiones demográficas, económicas y urbanas. Una verdadera crisis generalizada para la capital del virreinato del Perú, que puede ser estudiada desde

1 Para ampliar la información sobre el terremoto de 1746 puede consultarse: Pérez-Mallaína Bueno, Pablo E.: Retrato de una ciudad en crisis. La sociedad limeña ante el movimiento sísmico de 1746, Consejo Superior de Investigaciones Científicas, Escuela de Estudios Hispano-Americanos, Pontificia Universidad Católica del Perú, Sevilla, 2001.

2 Walker, Charles y Ramírez Castañeda, Ricardo: "Cuentas y cultura material: la reconstrucción del Real Palacio de Lima después del terremoto de 1746", Anuario de Estudios Americanos, LIX2, Sevilla, 2002, págs. 657-696. 
muy diversas perspectivas, según se enfatice en uno u otro de los aspectos enumerados. Con todo, hay una forma especialmente fructífera de enfrentarse a este acontecimiento: considerar el terremoto una circunstancia, un instrumento de observación social enfocado sobre el verdadero objetivo de estudio: analizar cómo un grupo humano se enfrenta a una crisis generalizada y cómo ese mismo grupo valora las causas y las consecuencias del desastre. Todo ello con la intención final de conocer mejor la sociedad limeña de mediados del siglo XVIII y tener un ejemplo más para saber cómo los seres humanos de diferentes épocas y lugares nos enfrentamos a una situación límite.

Hace treinta o cuarenta años, estudiar un acontecimiento, como un desastre natural, era considerado casi despectivamente por las modas historiográficas que propugnaban los grandes trabajos basados en series estadísticas de carácter demográfico o económico. Afortunadamente, en las últimas décadas, sin embargo, se ha producido una revalorización del gran acontecimiento, más que por la importancia intrínseca del hecho, por la gran cantidad y calidad de informaciones que suele generar.

En el caso del terremoto de 1746 los testimonios que produjo son realmente impresionantes: mucha gente escribió cartas a sus amigos contándoles lo sucedido, los eruditos redactaron crónicas, las autoridades largos informes, los envidiosos lanzaron libelos, los aduladores poemas lisonjeros, los afectados memoriales de queja, todo ello sumado a los pleitos con los vecinos por una y mil causas. En pocas palabras, al igual que el terremoto abre grietas que permiten ver el interior de la corteza terrestre, su impacto social abre una especie de ojo de cerradura que permite observar aquello que la sociedad mantenía oculto. Como decía George Duby, el gran acontecimiento es como un adoquín que se lanza a un charco, haciendo removerse ese fondo cenagoso que bulle en el basamento de la vida. ${ }^{3}$

Acercándonos con esta perspectiva al estudio de la crisis sufrida por la sociedad limeña a raíz del terremoto de 1746, podemos concentrar nuestro interés en estas tres preguntas, entre otras muchas que podrían formularse: ¿Con qué instituciones; con qué personas y con qué eficacia se hizo frente al desastre? ¿La lucha contra las ruinas, que constituían un enemigo común, contribuyó a suavizar o, por el contrario, agravó las tensiones sociales preexistentes? Y, finalmente, ¿cómo interpretaron los limeños las causas de la tragedia y cómo sintieron sus consecuencias?

3 Duby, Georges: Diálogos sobre la historia. Conversaciones con Guy Lardreau, Alianza Universidad, Madrid, 1988, pág. 59. 


\section{Instituciones y particulares frente a la catástrofe}

La primera de las cuestiones planteadas consiste en conocer cuáles fueron los organismos y las personas que hicieron frente a la destrucción ocasionada por el terremoto, así como el nivel de eficacia que tuvieron luchando contra las ruinas. En ese sentido, la respuesta que puede adelantarse es que los individuos, al grito de isálvese quien pueda!, fueron desprotegidos por las instituciones.

$\mathrm{Si}$ atendemos primero a la actuación de las autoridades civiles del virreinato, notamos que limitaron sus responsabilidades a tres aspectos concretos que consideraron su estricta obligación: la reconstrucción de los edificios administrativos y militares, el mantenimiento del orden público y la defensa de la propiedad privada. Aparte de estos asuntos, los burócratas peruanos no se sentían forzados a hacer otra cosa y así, por ejemplo, cuando al virrey, don José Antonio Manso de Velasco, fue acusado por algunos ciudadanos en su Juicio de Residencia de no haberse ocupado de dar cristiana sepultura a los cuerpos esparcidos entre los escombros, su abogado respondió que ésa no era labor del Estado, sino de la caridad pública, y que las autoridades cumplían con su deber impidiendo que los cadáveres fueran desvalijados por los ladrones. ${ }^{4}$

Realmente el único esfuerzo financiero realizado por la Real Hacienda del Perú para intentar paliar los daños personales sufridos por los limeños consistió en pagar algunas limosnas atrasadas a un par de hospitales que debían encargarse de curar a los heridos. De esta manera, se entregaron 4.000 pesos al Hospital de Indios y 6.000 al de negros, con lo que, al parecer, las autoridades coloniales tranquilizaron completamente su conciencia. ${ }^{5}$ Entregar 10.000 pesos de presupuesto que ya estaban asignados no puede considerarse, en efecto, ningún gasto excesivo. A modo de comparación podemos apuntar que el sueldo anual de cada oidor o alcalde del crimen, de los 19 que por entonces tenía la Real Audiencia, alcanzaba los 4.800 pesos y que ni en ese trágico año, ni en los inmediatos, ninguno de ellos dejó de recibir completamente su paga. De igual manera, la guardia militar del virrey, únicas tropas que quedaron operativas, tampoco tuvo dificultad alguna para recibir sus salarios íntegros.

4 Archivo General de Indias (en adelante, AGI), Lima, 787. "Representación Primera" de don Antonio de Boza en defensa del Conde de Superunda, sin fecha, hacia 1762.

5 AGI, Contaduría, 1770. Datos de la Caja de Lima correspondientes a 1747. 
Otro ejemplo de la poca voluntad de las autoridades civiles para ayudar más allá de lo que consideraban su estricta obligación fue el caso de la reconstrucción de la Catedral metropolitana. El Cabildo Eclesiástico, amparándose en el Regio Patronato, consideraba que pagar los trabajos era responsabilidad del monarca y de su representante, el virrey, el cual, no en vano, ostentaba entre sus títulos el de "vicepatrono" de la Iglesia del Perú. Las discusiones fueron agrias y llegaron a tal punto muerto, que el mayor templo del virreinato estuvo una década en ruinas. Al final, el virrey afrontó la responsabilidad, pero la Iglesia Metropolitana no se volvió a levantar de cal y canto, sino en madera y a expensas del fondo de las "vacantes eclesiásticas". Ésta era una renta de donde se sacaban tradicionalmente las limosnas pagadas en nombre del rey a menesterosos e instituciones caritativas, las cuales, al menos mientras duraron las obras, tuvieron que buscarse otras formas de subsistencia.

Ahora bien, ¿la reticencia a emplear dinero público en socorro de los afectados por el seísmo se debió tan sólo a una cuestión de límites de responsabilidad? ¿Acaso la Real Hacienda del Perú se encontraba en un momento crítico y no disponía de fondos? La verdad es que, si bien el virreinato había pasado por épocas más boyantes, las Cajas Reales tenían cierto superávit, pero éste no fue empleado para socorrer a los damnificados por el terremoto. No hay que olvidar que desde 1739 la monarquía libraba una costosa guerra contra Inglaterra, algunos de cuyos episodios más graves se habían suscitado en territorio americano. En 1746, la amenaza de un nuevo ataque británico, como los sufridos en Portobelo o Cartagena de Indias hacía pocos años, no estaba descartada, y por eso el principal esfuerzo financiero estuvo centrado en la defensa del conjunto del virreinato y no en la reconstrucción de su capital.

Entre luchar contra las ruinas y contra los ingleses, este último objetivo pareció más acuciante. De esta manera en 1747, el terrible "año después" de la catástrofe, en la Caja de Lima sobraron 800.000 pesos. La mitad de esta importante suma se empleó en pagar los gastos de una escuadra que desde España había llegado al Perú y los 400.000 pesos restantes se enviaron a la metrópoli. El virrey Manso de Velasco demostró ser muy eficaz remitiendo caudales a España, pues en sus 16 años de gobierno mandó tres millones de pesos, de los cuales dos millones y medio fueron enviados entre 1748 y 1752, el quinquenio clave en la reconstrucción de Lima. ${ }^{6}$

6 AGI, Contaduría, 1769 al 1772-B. 
Viéndose rodeado de tanta destrucción y miseria, ¿no tuvo acaso el virrey la tentación de desviar dinero para socorrer a los ciudadanos de Lima y acelerar su reconstrucción? Consta documentalmente que, en efecto, sí la tuvo y que pensó separar algunos miles de pesos más para este propósito, pero al informar a Madrid de sus intenciones, recibió una cariñosa pero enérgica reprimenda. Decimos "cariñosa", porque quien se la hizo fue su paisano, mentor y máxima autoridad de la monarquía, después del rey, el todopoderoso ministro don Zenón de Somodevilla, marqués de la Ensenada.

Manso de Velasco pertenecía a una especie de club de riojanos que por entonces dominó el gobierno metropolitano y peruano. En un determinado momento, de la Rioja procedían no sólo el ministro y el virrey, sino también el nuevo arzobispo de Lima, Pedro Antonio de Barroeta y Ángel, con lo que se producía un verdadero pleno regional entre los gobernantes con supremas competencias sobre el Perú. La correspondencia privada entre Manso de Velasco y Ensenada, que puede consultarse en el Archivo General de Indias, da cuenta de la confianza que había entre ambos, pues en vez de dirigirse al otro como "excelencia" se llamaban "paisano y amigo del alma", "paisano de mi vida" firmando "suyo hasta la muerte".

Fue gracias a esa fluida relación que el ministro le hizo ver al virrey que las necesidades generales de la monarquía estaban por encima de las particulares de alguna provincia, por muy dramática que éstas fueran, recordándole que él había sido nombrado, precisamente, para volver a convertir al Perú en lo que fue antaño: la principal fuente de plata con la que se aceitaba la pesada maquinaria del imperialismo hispano. Manso reconoció humildemente su error, y le comentó a su querido paisano que, en efecto, en aquellos momentos finales de la guerra lo más importante era estar preparados para negociar la paz desde una posición de fuerza y poder recuperar Menorca y Gibraltar. Lima podía esperar. ${ }^{8}$

Ahora bien, si la maquinaria estatal colonial se mostró sumamente avara a la hora de aportar recursos financieros, en lo que no ahorró fue en la emisión de decretos, órdenes y reglamentos para intentar dirigir las acciones de los particulares. En el fondo se trataba de la vieja queja del cronista Gonzalo Fernández de Oviedo, que criticaba a la monarquía por haber

7 AGI, Lima, 642 y 643

8 AGI, Lima, 643. El conde de Superunda al marqués de la Ensenada, Lima, 30 de marzo de 1748 . 
puesto en la empresa americana sólo papeles y buenas palabras, dejando que el esfuerzo y el dinero lo aportasen los particulares.

Pero una cosa es redactar órdenes y otra muy distinta es que éstas se lleven a la práctica y sean eficaces. En ese sentido, tampoco parece que la actuación de la burocracia virreinal resultase muy eficaz. Se intentó, por ejemplo, limitar por decreto la subida de los precios de los alimentos básicos y los materiales de construcción pero, a pesar de ello, muchos de estos productos alcanzaron incrementos de más del $400 \%$. Ya lo había advertido el virrey duque de la Palata, que dirigía el virreinato cuando sucedió el anterior gran terremoto de 1687, al exclamar: "cual poco obran las leyes en época de necesidad". ${ }^{9}$ Aunque, tal vez, el fracaso más sonado y trascendente de la política virreinal fue la imposibilidad de llevar a cabo el bienintencionado proyecto de reedificar la ciudad siguiendo unas elementales normas antisísmicas, las cuales pudiesen disminuir gran parte de las víctimas cuando la tierra inevitablemente volviese a temblar.

En aras del bien común, don José Antonio Manso ordenó derribar todos los pisos altos de las viviendas, para que en lo sucesivo Lima fuese una ciudad formada por casas de una sola planta con techumbres de madera. A pesar de que la medida parecía sensata en una tierra donde los movimientos sísmicos eran tan devastadores y frecuentes, cayó como una auténtica bomba, más destructiva aun que el terremoto, entre las familias más poderosas y ricas de la capital, que eran las que poseían viviendas de varias plantas. Éstas, rápidamente, buscaron un abogado y se lanzaron a la lucha en la Real Audiencia contra la decisión virreinal, escribiendo para ello largos alegatos que, incluso, hicieron circular impresos. La lectura de estos escritos es de enorme utilidad para penetrar en la mentalidad de los ricos propietarios limeños, ya que en la defensa de sus palacios y balconadas estaban, en realidad, luchando por el mantenimiento de un estilo de vida. ${ }^{10}$

Fueron muchos los argumentos utilizados por los propietarios de grandes mansiones, pero uno de ellos resume muy bien todos los demás: el alto valor simbólico que la arquitectura tenía representaba el poder de los habitantes de origen español frente a las "castas"; es decir, el resto de los grupos étnico-culturales que componían la ciudad. Para los que eran, o se sentían, pertenecientes al grupo privilegiado de los "blancos", una ciudad tal y como la quería Manso de Velasco se parecería demasiado a las aldeas

9 AGI, Lima, 87. El duque de la Palata al rey, Lima, 25 de junio de 1688.

10 AGI, Lima, 511. "Representación de don Manuel de Silva y La Banda ante la Real Audiencia de Lima”, 29 de mayo de 1747. 
de los "indios". En opinión de los poderosos criollos y peninsulares de Lima, "las cortes deben distinguirse de las aldeas", pues en caso contrario "nuestra humildad sería la soberbia de los naturales".

En la defensa de sus palacios, estos plutócratas demostraron muy poco pudor a la hora de reconocer la escasísima importancia que le otorgaban a la vida de sus convecinos más pobres. Por ello no dudaron en poner el ejemplo de la ciudad de Nápoles, en la que algunos años antes otro terrible movimiento sísmico había matado, según se decía, a más de 90.000 personas, sin que eso llegase a impedir la reconstrucción de sus edificios con igual altura y esplendor que antaño. ¿Qué importaba la muerte de unos pocos miles de desgraciados, frente a la magnificencia y el lujo de las cortes? ¿Acaso- decían los ricos limeños- los reyes evitan las guerras ante el temor de que en ellas murieran soldados en las batallas o inocentes en los sitios de las ciudades? ¿Evitan los comerciantes enviar sus barcos a los océanos ante el temor de que algunos de ellos se hunda y perezcan todos los tripulantes? ¡Claro que no! Porque según los propietarios de mansiones, la grandeza de las ciudades y los reinos era el verdadero bien común.

Pero los patricios limeños se contentaron con definiciones tan estremecedoras de lo que era el "bien común", sino que, dejando a un lado las teorías, decidieron pasar de las palabras a los hechos. Su procurador llegó a acusar al virrey ante la Audiencia de ser un "nuevo Nerón" pues, al igual que el déspota romano, Manso de Velasco deseaba destruir una antigua capital para levantarla a su antojo. Y tanta fue la presión realizada por estos prominentes ciudadanos, que la suprema autoridad del Perú se vio obligada en 1747 a retirar su proyecto de reforma urbanística de Lima, para evitar, según cuenta el propio virrey, tener que verse obligado a usar la violencia con las familias más distinguidas de la ciudad. ${ }^{11}$ Para el supremo gobernante colonial fue una auténtica derrota que recordaría largo tiempo y que muchos años después seguiría reflejando con amargura en su "Memoria de Gobierno".

Gracias a la presión de los propietarios, Lima siguió siendo una corte con palacios y grandes edificios, pero con sus partes más elevadas construidas en madera o con cañas embarradas y enlucidas, es decir, utilizando el sistema conocido como "quincha", que ya usaban muchas culturas antes de la llegada de los españoles. Lo curioso es que en el mundo de las apariencias, especialmente presente en aquellos barrocos tiempos, el alma de

11 Ibídem. Don José Manso de Velasco al rey, Lima, 20 de junio de 1748. 
madera se ocultaba bajo el aspecto de falsos recubrimientos que imitaban otros materiales. El instinto de supervivencia aconsejaba construir de esta manera, pero la mentalidad forzaba a copiar los modelos de Castilla o de Andalucía, lugares en los que los terremotos no representan una amenaza tan seria.

En vista de que las autoridades civiles no hicieron demasiado por remediar los problemas más acuciantes y graves del conjunto de la población, ¿serían las autoridades eclesiásticas las que se ocuparían de ellos? Desafortunadamente, la Iglesia, como institución y con sus principales dirigentes al frente, tampoco realizó una labor muy eficaz en este sentido. Es evidente que los conventos daban limosnas, pero en aquellas graves circunstancias también las pedían. Así sabemos por un informe del mayordomo del Hospital de Indios de Santa Ana, que le resultaba inútil salir a las calles a pedir dinero para su institución, pues no podía competir con los cientos de frailes que hacían lo mismo para reconstruir sus conventos. ${ }^{12}$

Tal vez el que la Iglesia, de una forma institucional, no encabezase la política de ayuda a los damnificados y posterior reconstrucción de la ciudad pudo deberse en gran parte a la personalidad de quien ocupaba la cúspide jerárquica, el nuevo arzobispo de Lima, don Pedro Antonio Barroeta y Ángel. Es verdad que este eclesiástico llegó algún tiempo después del temblor, pero todavía quedaba mucho por hacer. Riojano, como el virrey y Ensenada, había sido elegido por este último como hombre de confianza, y al recibir su nombramiento, el ministro le advirtió que se le enviaba a una ciudad en ruinas en la que debía poner especial empeño en auxiliar a los pobres, huérfanos y "estropeados". Barroeta, por su parte, respondió que para poder desempeñar esa caritativa labor sin el lastre de los empeños y las deudas, la Corona debía ayudarle a pagar el largo viaje desde España al Perú. Su demanda fue atendida, y se le autorizó a resarcirse de tal desembolso cobrándolo de la renta de vacantes eclesiásticas de Lima, de cuyos fondos, como ya se explicó, solían salir muchas de las limosnas pagadas por el rey. El problema fue que a su llegada el arzobispo presentó al virrey una factura de gastos, avalada tan sólo por su palabra, de nada menos que 109.000 pesos, cantidad con la que podía mantenerse el único hospicio de Lima durante ocho años. Tras pagar una parte, Manso de Velasco comunicó a la Corte que la caja de vacantes había quedado vacía y que no restaba

12 "Información que dan el mayordomo y diputados del Real Hospital de Señora Santa Ana", Revista del Archivo Nacional, XII-2. a, Lima, 1939, pág. 179. El documento en cuestión está fechado el 26 de febrero de 1748 . 
nada para los piadosos fines a los que el rey solía destinar aquellos fondos? Los "estropeados" de Lima tendrían que aguardar otra oportunidad. ${ }^{13}$

Don Pedro Antonio de Barroeta nunca fue un arzobispo popular entre sus feligreses limeños, y todo parece indicar que tampoco fue la persona adecuada para capitanear una acción solidaria. Entonces ¿quién ejerció esta labor en tiempos tan difíciles? Para responder a esa pregunta hay que considerar que en la Lima de mediados del siglo XVIII la caridad era una virtud realizada en nombre de principios religiosos, pero ejecutada y financiada mayoritariamente por cofradías de seglares.

Las autoridades religiosas se preocupaban mucho más por el espíritu que por el cuerpo y por ello, además de mantener el culto sagrado, se ocupaban de la enseñanza, vía directa para penetrar en el interior de las conciencias. Como contraste, de los 11 hospitales de Lima (contando el único orfanato), sólo tres estaban regentados por órdenes regulares. Los otros ocho, incluyendo los más importantes, los dirigían cofradías de "hermanos veinticuatro" y se financiaban con mandas testamentarias privadas. Otras cofradías similares eran las que, por ejemplo, se encargaron de enterrar a una buena parte de las víctimas del temblor, lo mismo que hacían regularmente con los indigentes y pobres de la ciudad.

De la dedicación, competencia y generosidad de los mayordomos y hermanos de estas cofradías dependía la reconstrucción de la red sanitarioasistencial del virreinato. De este hecho han quedado reflejos en el propio lenguaje castellano, pues uno de los "peruanismos" aceptados por la Real Academia de la Lengua Española es "barchilón", que, según nos informa en su Diccionario, proviene del apellido de un español caritativo del Perú en el siglo XVI y que ha quedado como sinónimo de "enfermero".

Dentro de este grupo de anónimos benefactores, cabe destacar el nombre de uno de ellos: don Diego Ladrón de Guevara, mayordomo del único hospicio de Lima. Gracias al esfuerzo y al patrimonio personal de este personaje pudo rehacerse el hospicio, sin ninguna ayuda pública, pues cuando fue a solicitarla, se le comunicó que los fondos estaban dedicados por completo a la reconstrucción de la catedral. ${ }^{14}$ Como todo hombre solidario, don Diego tenía una personalidad emprendedora, pero tal vez un poco ingenua. Así, llegó a proponer al virrey que, como él conocía bien a los pobres de Lima, se le podía nombrar receptor de todas las limosnas que entregasen

13 AGI, Lima, 988. El conde de Superunda al rey, Lima, 1 de octubre de 1751.

14 AGI, Lima, 420. "Compulsa de los autos y diligencias actuadas sobre la reedificación de la casa de los niños expósitos de esta ciudad”. Los Reyes, 20 de enero de 1757. 
los particulares, encargándose de que éstas fuesen a los lugares y personas más necesitadas. Don Diego no comprendía que dar limosna no sólo era un acto de caridad, sino también una demostración de calidad social y el hecho de que los nobles limeños tuviesen a su puerta una legión de menesterosos a la espera de un tazón de sopa suponía tal prestigio al dueño de la casa, que podía salir de ella en una carroza tirada por cuatro caballos. Al final sus proyectos asistenciales no se financiaron con una limosna general y de justicia, como pedía, sino con una contraprestación a la frivolidad, haciendo que el empresario de la plaza de toros le pagase una especie de impuesto caritativo de 1.500 pesos al año.

Con todo, en Lima funcionaba, o mejor, debía funcionar un sistema organizado de ayuda mutua para algunos de los más pobres de sus habitantes, como eran los indígenas residentes en la capital y en otros lugares del virreinato. Me refiero a la Caja de Censos de Indios, puesta al cuidado de un oidor de la Audiencia, en la que se separaba dinero procedente de los tributos. La idea era que estas cantidades se prestasen a interés a solicitantes solventes y los beneficios obtenidos fueran empleados en provecho de los propios indios. El problema consistía en que dicha institución era uno de los focos más importantes de corrupción, cohecho y malversación del virreinato, y alrededor de la miel de sus fondos pululaban cientos de aprovechados. Como ejemplo baste saber que en el mismo mes en el que el mayordomo del Hospital de Indios de Santa Ana se quejaba de no tener dinero para reconstruirlo, la Audiencia concedió un préstamo de 40.000 pesos de la Caja de Censos al conde de Santa Ana de las Torres para reconstruir sus casas y haciendas destrozadas por el seísmo. ${ }^{15}$

El conde era uno de los más prestigiosos aristócratas de Lima. Su familia poseía una capilla en la catedral, donde todavía hoy puede contemplarse la estatua orante de su padre, en honor del cual se compusieron hermosas piezas de guitarra barroca. Con todo, la desordenada vida del joven aristócrata y el excesivo lujo con el que residía en la corte de Madrid lo habían arruinado. Nadie quería prestarle dinero y acudió a sus influencias para conseguirlo de la Caja de Censos de Indios, con la esperanza de no tener nunca que devolverlo. El hecho fue que los fondos destinados a aliviar a los indios se prestaban a un noble que, según el fiscal del Consejo de Indias, había dilapidado su fortuna viviendo en España como un gran señor

15 AGI, Lima, 515. "Expediente del conde de las Torres sobre imponer en su mayorazgo cierta cantidad de pesos de la Caja de Censos de Indios destinados a reparar sus propiedades destruidas por el terremoto de 1746 ". 
y al que en Lima ningún particular había querido adelantarle ni un real. Cuando a raíz de este y otros escándalos similares uno de los fiscales de la Audiencia de Lima destapó las corruptelas de la Caja de Censos, el propio monarca pidió explicaciones al virrey. Éste le contestó que, en efecto, muchos habían sido los préstamos que no se habían recuperado, pero que era difícil tomar alguna acción punitiva, pues el primer beneficiario había sido la propia Real Hacienda, la cual, a mediados del XVIII, adeudaba dos millones y medio de pesos a la Caja de Censos de Indios.

\section{Terremoto y tensiones sociales}

Podemos preguntarnos si la lucha contra ese enemigo común que era la fuerza desatada de la naturaleza actuó como un bálsamo capaz de suavizar las evidentes tensiones de aquella sociedad. La verdad es que en los primeros momentos la gente confesaba en público sus pecados, perdonaba a gritos a todos, hasta a sus más mortales enemigos, y se avenía, por fin, a llevar al altar a quienes habían sido sus mancebas o amantes. Sin embargo, pasados esos momentos iniciales de comunión, las ruinas tuvieron una acción contraria y sirvieron para avivar viejos conflictos y aún para crear otros nuevos.

Refiriéndonos primero al interior de los grupos privilegiados, el movimiento sísmico llevó a algunas de las más ricas familias limeñas a un enfrentamiento directo con el virrey y puso de manifiesto la fractura existente entre los destacados miembros de la sociedad civil y el clero regular. A don José Antonio Manso de Velasco le sorprendió la catástrofe cuando llevaba poco más de un año al frente del gobierno y seguramente todavía no conocía bien cuáles eran los límites de su poder. Fue precisamente la crisis ocasionada por el terremoto la que le enseñó con toda rapidez cuáles eran las cosas que podía hacer y cuáles no.

Ya hemos comentado su sonora derrota política ocurrida en 1747, cuando, al año siguiente de ocurrida la catástrofe, tuvo que renunciar a la principal medida de urbanismo antisísmico consistente en derribar los pisos altos de todas las viviendas capitalinas. En 1748 las tensiones con el patriciado urbano fueron mucho peores: el virrey se opuso a que los propietarios de las casas de Lima aprovechasen la coyuntura para dejar de pagar las cuantiosas deudas que tenían con la Iglesia, y en especial con los distintos conventos y órdenes religiosas, en forma de censos. 
No sería exagerado decir que Manso de Velasco tuvo que enfrentarse a un verdadero "motín de privilegiados". Un centenar de notables, en los que se incluían 10 títulos de Castilla, de los aproximadamente 40 que entonces tenía Lima, solicitaron un Cabildo Abierto y redactaron proclamas que podían haber sido perfectamente suscritas por las instituciones municipales que varias décadas más tarde proclamaron la independencia en muchos puntos del continente. No le quedó entonces más remedio que amenazar por medio de la fuerza, iniciando un proceso criminal por conspiración contra los firmantes del escrito. ${ }^{16}$ Esta vez fue suficiente con amagar el golpe, pero el virrey sacó una conclusión: no se podía gobernar contra los intereses de los patricios limeños teniendo bajo sus órdenes tan sólo a la compañía de soldados de su guardia, única fuerza militar que le quedó después de la desaparición de la guarnición de El Callao tragada por el mar. Tras esta experiencia, el gobernante debió comprender que era hora de seguir la vieja máxima: si no puedes vencerlos, únete a ellos. Y, en efecto, para los años siguientes se preocupó de buscar el apoyo de la que llegó a ser una de las redes de clientes más importantes de la capital.

No hay que olvidar que para comprender la acción de gobierno de los altos responsables de la administración colonial, no sólo hay que conocer su biografía o antecedentes familiares, sino también la de la camarilla formada por sus consejeros y asesores, más los ayudantes de éstos últimos denominados "agentes", todos los cuales formaban una especie de gabinete ministerial, que compartía con el virrey su acción de gobierno. Pues bien, a partir de 1748, Manso de Velasco escogió para formar este grupo a algunos representantes de destacadas familias criollas. Así el "asesor de españoles" fue don Francisco Hervoso, un canónigo limeño cuyo padre había sido presidente de la Audiencia de Charcas. El "asesor de indios", don Antonio Boza, era chileno, pero se casó con la primogénita de los marqueses de la Casa Boza, una de las familias más nobles de la ciudad, mientras que sus dos principales consejeros fueron los oidores criollos, don Pedro Bravo de Rivero y don Pedro Bravo de Lagunas y Castilla. Éstos últimos, a pesar de la coincidencia de apellidos, no eran parientes de sangre, un pequeño inconveniente que solucionaron rápidamente casándose con dos hermanas del poderoso clan de los Zabala y estableciendo así un firme parentesco político. ${ }^{17}$

16 AGI, Lima, 983. El conde de Superunda al rey, Lima, 18 de diciembre de 1748. El virrey adjunta a esta carta los autos completos sobre lo que él entendió como un conato de sedición.

17 AGI, Lima, 1586. El arzobispo de Lima al inquisidor general, Lima, 31 de marzo de 1758 En esta carta Barroeta expone las actividades y relaciones de estos poderosos personajes. 
Gracias a las experiencias de sus fracasos y con la ayuda de sus nuevos aliados, el virrey ya no estuvo solo a la hora de controlar a las elites locales, y pudo desarrollar su acción de gobierno a lo largo de un total de 16 años, lo que constituye el periodo más largo de cualquier supremo gobernante colonial. Como contrapartida negativa hay que señalar que el círculo que formaban sus colaboradores inmediatos resultó ser uno de los grupos de presión más eficaces, pero también de los más proclives a utilizar en beneficio propio los resortes de la autoridad que ejercían.

Y ya que nos referimos a las formas que adoptaba en Lima la lucha por el poder, debe destacarse que el terremoto incrementó dos de sus instrumentos clave: la adulación y la calumnia.

Para un gobernante colonial, vivir una catástrofe natural mientras ejercía su cargo podía suponer, aunque parezca contradictorio, un claro golpe de fortuna. Frente a este tipo de desgracia no cabía, como en el caso de sufrir una derrota militar, el deshonor y era una ocasión magnífica para el lucimiento personal, que bien administrado podía proporcionar incluso un título de nobleza. Así le ocurrió a don José Antonio Manso, que se vio elevado a la condición de noble titulado con el expresivo título de conde de Superunda (por haberse impuesto a las olas que arrasaron el puerto de la capital). Una situación parecida a la de don Sebastián José de Carvalho, que gracias a sus servicios a la monarquía portuguesa, entre los que destacaba la reconstrucción de Lisboa tras el maremoto de 1755, terminó convertido en marqués de Pombal.

Debe reconocerse que don José Antonio Manso fue un maestro en el uso propagandístico de la imprenta, favoreciendo la publicación de una serie de escritos en los que se dejaba adular sin el menor recato. Aprovechando la proclamación del nuevo rey, Fernando VI, o la inauguración de alguna de las fases de la reconstrucción de la catedral, eruditos locales realizaban verdaderos panegíricos de la acción del virrey. También hubo otras plumas más imparciales que comentaron los errores del gobernante, pero ninguno de esos escritos llegaron a publicarse en Lima y es por eso que alguno de sus enemigos llegó a afirmar que las alabanzas de sus criados lo hicieron conde.

Esta última afirmación quizá fuese exagerada, pues no hay duda de que el virrey se mostró muy activo y personalmente implicado en calmar la angustia de los limeños, pero en cualquier caso, los panegiristas lo dibujan como una figura casi sagrada que, con los brazos abiertos y montado en un caballo blanco, recorría las calles calmando la tempestad de las masas. 
Algunas de las adulaciones recibidas por Manso de Velasco producen sonrojo y llegan a constituir verdaderas letanías profanas. Así se le denomina "luz de nuestros corazones", "sol que sazona los frutos", "argonauta del celo real", "arco del diluvio": "única y segura columna en que descansa la máquina de este Nuevo Mundo". A tanto llegaron los halagos, que algunos alcanzaron a traspasar la débil frontera que separa lo sublime de lo ridículo. De esta manera se puso por escrito que ya que su larga y noble parentela le impedía ser "el primer Manso", no le pudo estorbar ser "el mayor de los Manso". ${ }^{18}$

Pero no fue únicamente el virrey quien aprovechó la ocasión en su beneficio. Tal vez uno de los mayores expertos en arrojar incienso sobre su propia persona fue don Pablo de Olavide. Al por entonces joven oidor de la Audiencia de Lima se le ordenó venir a España para defenderse de una grave acusación: el haberse quedado con bienes que tenía en depósito, fingiendo que se habían perdido entre las ruinas. Pues bien, a pesar de que los cargos eran de índole tan vulgar y tan alejados de la épica lucha por la ilustración de los pueblos, él mismo, o alguno de sus amigos, inventó la persistente leyenda de que la verdadera razón de su salida de Lima fue la persecución a que fue sometido por las fuerzas más conservadoras de la sociedad. El motivo de esta inquina se debió, según la leyenda, a su decisión de preferir reconstruir un teatro antes que una de las iglesias derribadas por el terremoto. Los documentos del Archivo General de Indias indican con toda claridad que Olavide nunca estuvo al frente de ninguno de los trabajos de reconstrucción y que toda esa romántica idea del perseguido por la caverna más recalcitrante no fue sino una hábil cortina de humo para ocultar los pecados de juventud de quien habría de ser, en el futuro, una de las figuras más importantes de la Ilustración hispana. ${ }^{19}$

Ahora bien, como indica el viejo refrán castellano, "las cañas se tornaban lanzas" con mucha facilidad y lo mismo que la catástrofe podía aprovecharse para labrarse un porvenir, una imagen pública o conseguir un título de nobleza, también podía ser empleada para fabricar tremendas calumnias contra el prójimo. Así, por ejemplo, cuando el conde de Superunda dejó de ser virrey del Perú, lo acusaron de haberse quedado con los bienes de los centenares de personas que perecieron en el maremoto de El Callao y cuyos cuerpos fueron devueltos a la playa por el mar; es

18 Pérez-Mallaína: Retrato de una ciudad..., págs. 268-274.

19 Defourneaux, Marcelin: Pablo de Olavide el afrancesado, Padilla Libros, Sevilla, 1990, pág. 28.

AEA, 62, 2, julio-diciembre, 2005, 47-76. ISSN: 0210-5810 
decir, una vez que dejó el poder, sus enemigos le imputaron algo terrible: haber hurgado en los bolsillos de los cadáveres para desvalijarlos. De igual manera, al doctor Arenaza, que por entonces ejercía la función de visitador de la Inquisición de Lima y que en el ejercicio de su oficio había levantado más de una ampolla, se le adjudicaron todo tipo de infundios y de acusaciones de contenido personal, más explícitamente, sexual, como el haber escapado a caballo la noche del temblor llevando a su amante desnuda en la grupa. ${ }^{20}$

Ahora bien, dejando a un lado las rencillas personales, resultan más significativos los desencuentros entre importantes sectores sociales que la ruptura del orden ponía de manifiesto. En este sentido es digna de atención la importante fractura evidenciada entre destacados miembros de la sociedad civil, por un lado, y el clero regular limeño, por otro, con relación al mantenimiento o supresión de los censos tras el terremoto.

No había casa particular de alguna consideración en la capital que no estuviese gravada con varios censos, cuyos beneficiarios eran, en su inmensa mayoría, instituciones religiosas y, en especial, alguno de los muchos conventos de frailes y monjas de la ciudad. Sin entrar en tecnicismos digamos que para la Iglesia los censos eran una especie de celosía jurídica que trataba de difuminar las actividades financieras del clero. En realidad una buena parte de los censos no era otra cosa que préstamos a interés con garantía hipotecaria, pero para tratar de maquillar el cobro de los réditos se consideraba que lo que se recibía al final de cada año no era un porcentaje de un determinado capital, sino la consecuencia de haber comprado una renta fija. Una sutil interpretación, muy propia de quienes están habituados a hilar muy fino en el campo de las ideas. Cuando un convento dejaba a un particular una cantidad de dinero, no le prestaba, sino que estaba adquiriendo el derecho a recibir una cantidad todos los años, que el resto de los mortales llamaba interés y ellos consideraban una renta.

La catástrofe rompía este tipo de entelequias morales y jurídicas, y mostraba con toda claridad el carácter de principales banqueros de la sociedad civil que tenía el clero regular. Los propietarios cuyas casas habían sufrido daños se apresuraban a defender que, si en verdad los censos eran otra cosa distinta a una hipoteca, los censualistas y los censatarios deberían compartir las pérdidas. Por el contrario, las autoridades religiosas defen-

20 Anónimo: "Descripción de la ciudad de Lima, capital del reino del Perú...", Biblioteca Nacional de Madrid (en adelante, BNM), 11026s, 49. 
dieron con toda firmeza que, aunque los edificios se hubieran destruido hasta los cimientos (y a pesar de que en ese caso era imposible que aquel bien produjese ningún tipo de renta), la obligación de pagar los principales e intereses debía permanecer inalterable.

Ante semejante diferencia de puntos de vista, ambos bandos nombraron sus representantes oficiales para pleitear y defender ante el virrey y la Audiencia sus contrapuestos planteamientos. El resultado fue un largo cruce de acusaciones vertidas en incendiarios escritos en los que ambas partes se hacían durísimas recriminaciones. Tan agrias fueron las disputas que el conde de Superunda comentó en su memoria de gobierno que una de las mayores desgracias que trajo a la ciudad el terremoto fue el enfrentamiento entre censualistas y censatarios. ${ }^{21}$ En ese sentido los propietarios de los inmuebles llegaron a calificar la actitud del clero como "repugnante y odiosa", indicando que los religiosos se complacían en explotarlos a ellos, orgullosos descendientes de los conquistadores, como si fuesen simples indios. $\mathrm{Y}$ es que los tribunales eclesiásticos empezaron a ejecutar las deudas de muchos particulares y, en ese momento, el que hasta entonces había sido un bondadoso capellán que, gracias al provecho de un censo, decía misas por el eterno descanso de los abuelos, se convertía ahora en una especie de ave de rapiña capaz de embargar la vajilla de plata, uno de los pocos bienes que se había salvado de entre los escombros.

El virrey y las autoridades civiles fueron en principio favorables a disminuir la presión de los censos, pues las propias rentas de la real Hacienda se encontraban también gravadas con este tipo de cargas; sin embargo, con todo, al final no tuvieron más remedio que ejercer un papel mediador entre ambos bandos. Como medida salomónica se decidió finalmente no alterar el valor de los principales de las deudas, pero sí moderar ligeramente los intereses. Con ello el Estado contuvo lo que hubiese sido un verdadero expolio para los bienes de la Iglesia. Al fin y al cabo el estamento eclesiástico era su principal aliado en la difícil tarea de dominar un imperio tan vasto y tan variado, y no podía permitir su ruina. Ahora bien, este tipo de conflictos permite rastrear los orígenes del feroz anticlericalismo de importantes sectores privilegiados en el siglo posterior. Así se comprende con toda claridad que cuando los criollos subieron al poder tras producirse

21 Fuentes, Anastasio (ed.): Memoria de los virreyes que han gobernado el Perú durante el tiempo del coloniaje español. Relación que escribe el conde de Superunda..., Librería Central de Felipe Bailly, Editor, Tipografía de Agustín Mena y Cía., tomo IV, El Callao, 1859, págs. 115-116. 
la independencia, la suerte de los censos y de otros muchos bienes de la Iglesia estuvo definitivamente echada.

Las autoridades virreinales habían impedido que los propietarios de las casas de Lima se liberaran del dogal con que les tenían atados muchos conventos pero, a pesar de ese apoyo, el propio virrey era consciente de lo dañino que podía ser para la sociedad la hipertrofia del clero regular limeño. Tal vez, la propia naturaleza, con el derrumbe de muchos claustros e iglesias conventuales, estaba dando la oportunidad soñada para limitar el número de estas instituciones y de sus componentes.

En 1746 en Lima había 44 conventos. Eran menos que los 55 que por entonces tenía Madrid o los 77 de Sevilla, aunque ambas ciudades peninsulares eran más populosas. ${ }^{22}$ En total, puede calcularse que el clero regular suponía aproximadamente el 5\% de la población limeña, que por entonces rondaba los 60.000 habitantes. Era una proporción muy alta y luego del terremoto pareció aun mayor. Rotas las clausuras y las tapias conventuales, una auténtica marea, casi tan poderosa como la que anegó El Callao, pareció llenar la capital virreinal de tocas, velos y capuchas.

Para el virrey y también para el marqués de la Ensenada y otros políticos peninsulares, esta superabundancia de monjas y frailes producía malos ejemplos, por la evidente falta de vocación de muchos de ellos, así como una clara asfixia económica de una población presionada por las demandas de limosnas y privada de muchos bienes que quedaban ligados al régimen de manos muertas de los conventos. Los religiosos estaban comenzando a dejar de ser vistos como intermediarios necesarios ante la divinidad, para considerarlos como verdaderos parásitos desde el punto de vista económico.

El conde de Superunda escribió al rey y a su protector, el marqués de la Ensenada, indicándoles que aquél era el momento de no reconstruir muchos de los conventos arruinados. El ministro, tras meditarlo y reunir la correspondiente junta consultiva, apoyó la idea y expidió las órdenes oportunas. ${ }^{23} \mathrm{Y}$, sin embargo, tales órdenes no sirvieron para nada. ¿Qué ocurrió? Pues que la realidad se impuso a la teoría del reformismo borbónico. La realidad hecha distancia y burocracia, mientras el proyecto de reducción de conventos de Lima llegó a Madrid, fue estudiado y volvió la respuesta

22 AGI, Lima, 984. "Nota de las comunidades religiosas que había en la ciudad de Lima en el reino del Perú", hacia 1749. Aguilar Piñal, Francisco: Historia de Sevilla. Siglo XVIII, Universidad de Sevilla, Sevilla, 1982, págs. 130 y 189.

23 AGI, Lima, 415. El conde de Superunda al rey, Lima, 10 de diciembre de 1746. 
regia, pasó tanto tiempo que la mayoría de los conventos estaban ya reconstruidos o en fase muy avanzada de restauración. ¿Acaso se podían haber hecho las cosas con mayor rapidez? Posiblemente no, pues era un asunto delicado que merecía todo tipo de cautelas. La medida de reducir el número de conventos habría sido muy impopular entre muchos blancos pobres y mestizos, que tenían en ellos, y en las órdenes que los regentaban, uno de sus escasos canales de ascenso social. Pero es que, además, entre los propios sectores privilegiados, el clero regular tenía un importantísimo aliado entre las mujeres.

Bien a las claras conoció el virrey el poder del elemento femenino. En sus memorias de gobierno, el conde de Superunda comentaba que ya que El Callao había sido arrasado y que el nuevo puerto de Lima tenía que alzarse de nueva planta, la población que lo sustituiría, denominada Bellavista, debía construirse con una sola parroquia y sin ningún convento, con lo cual no contaría con un número superfluo de bocas que alimentar. ${ }^{24}$ Fue una idea brillante e ilustrada, pero no la pudo llevar a cabo. Sin conventos, las esposas de los funcionarios civiles y militares allí destinados no estaban dispuestas a trasladarse y sin ellas, tampoco irían sus maridos. Porque para una población, y especialmente para una de nueva creación, la falta de conventos significaba ausencia de colegios para la educación de los niños, pero también carencia de triduos, novenas, rosarios, sermones, confesores, que en aquella sociedad constituían la única ocasión que tenían las mujeres de burlar el férreo aislamiento a que eran sometidas y relacionarse honorablemente con otras personas fuera del ámbito familiar.

Por otra parte, eliminar radicalmente los conventos femeninos hubiese sido muy complicado habida cuenta de las muchas funciones sociales que cumplían, tanto para las mujeres como para los hombres. Todos los textos que cuentan los sucesos del terremoto indican con claridad que una de las consecuencias más inquietantes de la tragedia fue la caída de las cercas conventuales. Para la mayoría, el derrumbe de estos muros y la ruptura de las clausuras constituía el principal símbolo del desorden y la confusión que atenazaba la ciudad en aquellas tristes horas. Por el contrario, la restauración de las tapias significaba la vuelta a la normalidad.

Podemos preguntarnos por qué este hecho producía tanta zozobra en las horas trágicas en las que había otras fuentes importantísimas de preocupación. La respuesta es doble: en primer lugar, hay que considerar que los

24 Fuentes: Memoria de los virreyes..., pág. 123. 
conventos, especialmente los de monjas, eran considerados una especie de isla de pureza entre los océanos de maldad del mundo exterior. Allí, al menos en teoría, se encerraban unas candorosas vírgenes cuya misión era servir de intermediarias entre la divinidad y los pecadores. Por ello, en un momento en que, tal y como consideraba la opinión mayoritaria, Dios había castigado la maldad de los hombres mandándoles un terremoto, era más necesario mantener activos aquellos centros que podían, con sus oraciones, contribuir a calmar su santa ira.

Sin embargo, había una segunda e importante razón para que los limeños anduvieran desasosegados con la desaparición de las barreras que cerraban las clausuras. Las visitas de arzobispos como Morcillo o Barroeta a los conventos limeños habían puesto en evidencia que tras sus tapias lo que menos había eran monjas profesas. ${ }^{25}$ Por el contrario, sus espaciosos claustros servían de refugio a una gran cantidad de mujeres viudas, solteras y, lo que era más preocupante, a un buen número de casadas y separadas de sus esposos o "divorciantes", como se las denominaba en los textos de la época, a las que se unían antiguas amantes de miembros de la oligarquía que encontraban allí refugio acompañadas de sus hijos ilegítimos. Si a todas ellas se sumaban sus abundantes criadas, se comprenderá la interesante mezcla humana de aquellos conventos. Tan abigarrado conjunto de personas resulta muy interesante para un historiador actual, pero suponía algo realmente inquietante para muchos de los limeños de mediados del XVIII. No hay duda de que las tapias conventuales encerraban muchas situaciones irregulares e incómodas para ellos, y eso contribuía al nerviosismo por verlas caídas.

Podemos poner un ejemplo concreto de un poderoso ciudadano, que debía preferir que los muros de las monjas fueran lo más altos posibles. Así, según se expone en un informe del propio arzobispo Barroeta, el oidor don Pedro Bravo de Lagunas escondía a varias de sus amantes zambas entre las criadas de un convento, a donde, según explica la misiva del prelado al rey, las iba a buscar en coche a la caída de la tarde. ${ }^{26}$ Sea o no cierta esta dañina información, lo que sí evidencia es la existencia de conductas semejantes a la aquí descrita que llevaría a muchos patricios a oponerse a las ocurrencias de todo aquel político, por muy ilustrado que fuese, que

25 AGI, Lima, 521. Don Diego Morcillo al rey, Lima, 11 de julio de 1725. Don Pedro Antonio Barroeta al rey, Lima, 22 de diciembre de 1755.

26 AGI, Lima, 524. Don Pedro Antonio Barroeta al rey, Lima, 15 de septiembre de 1755. 
pensase en terminar con una docena de conventos, dejando a la vista los más oscuros secretos del pasado de cada cual.

Ahora bien, si hasta el momento hemos comentado únicamente las disputas ocurridas en el seno de los grupos privilegiados, que son las mejor documentadas, la confusión provocada por el terremoto también produjo tensiones entre los sectores más poderosos y los más desfavorecidos.

En primer lugar, de la lectura de los documentos oficiales y particulares se desprende que los patricios temieron que el desorden fuera aprovechado por ese abigarrado conjunto de mestizos que se agrupaban en las llamadas "castas", y por los esclavos negros, para rebelarse contra el poder de peninsulares y criollos. ${ }^{27}$ Ahora bien, a pesar de estos temores, hay que reconocer que aunque existieron robos y pillaje, la temida rebelión generalizada no llegó a producirse.

La razón de esta aparente paz social no estuvo, a pesar de la propaganda del virrey, en la habilidad con que supo emplear sus reducidas fuerzas. Por muy activos que estuviesen sus soldados, sólo contaba con su guardia personal, apenas unos doscientos hombres. Con ellos le hubiera sido imposible contener cualquier motín y más cuando tampoco podía organizar a las milicias ciudadanas, pues sus componentes estaban dispersos y los pocos que se hubiesen quedado no tenían donde concentrarse, ya que las plazas estaban llenas de escombros.

Fueron otras las explicaciones que permiten comprender la falta de reacción inicial por parte de los grupos étnicos más oprimidos. En primer lugar, es evidente que la plebe urbana estaba seriamente dividida y que, por ejemplo, los indígenas y los esclavos negros se odiaban ferozmente. Pero además, se suele olvidar que para los que sólo tenían la vida para perder, el terremoto proporcionaba indudables beneficios a corto y mediano plazo.

En primer lugar, los trabajos de desescombro y posterior reconstrucción de la ciudad emplearon a todos los miembros de la plebe que deseaban trabajar y todo ello durante varios años y con unos salarios superiores a los normales. Terminar de derribar una casa particular podía suponer varios miles de pesos en salarios para los obreros y otros tantos el volver a levantarla. ${ }^{28}$ Los datos que poseemos de las reparaciones efectuadas en los edifi-

27 Flores Galindo, Alberto: La ciudad sumergida. Aristocracia y plebe en Lima, 1760-1830, Editorial Horizonte, Lima, 1991, pág. 123.

28 Archivo General de la Nación (en adelante AGN), Lima, Real Audiencia, Causas Civiles, 111, cuaderno 937. En este documento se indica que el licenciado Ignacio de Heredia pagó un millar de pesos por el desescombro y derribo de dos casas que poseía en Lima y que fueron seriamente afectadas por el terremoto. 
cios oficiales nos hablan de que sólo en el levantamiento de las nuevas fortalezas del puerto trabajaron 500 peones durante muchos años y que en reconstruir el conjunto de las casas reales, incluyendo el palacio, salas de la Audiencia etc. se consumió en jornales más de medio millón de pesos, que a seis reales diarios supusieron unas 700.000 peonadas en quince años..$^{29}$

Por otra parte, como tras el terremoto los ricos abandonaron la ciudad y se dirigieron a sus casas de recreo y haciendas campestres, los desfavorecidos de la fortuna se lanzaron sobre las ruinas y no hubo marco de ventana, puerta, viga o reja que no se llevasen. Con estos materiales extraídos de entre los escombros surgieron en las plazas, huertas y solares, algunos bastante céntricos, una nueva Lima de chabolas, donde los pobres no vivían peor que en los antiguos "callejones" y además lo hacían en lugares más céntricos y en muchos casos sin pagar alquiler. Hay pruebas documentadas de que algunos de estos alojamientos provisionales llegaron a durar treinta años. ${ }^{30}$

Con todo, el conflicto social más interesante tuvo efectos retardados y quedó únicamente en una tentativa, que, de haberse hecho realidad, podría haber llenado de violencia y sangre la ciudad de Lima. Nos referimos a la conspiración de varios indígenas del barrio de El Cercado, que consideraron que la confusión provocada por el temblor era una ocasión propicia para levantarse contra los blancos y asesinarlos a todos, incluido el virrey. El complot salió a la luz años más tarde, concretamente en 1750, y entonces quedó demostrado que las primeras reuniones de los conjurados tuvieron lugar poco después del terremoto, alentados al contemplar cómo los símbolos del poder español se encontraban caídos por los suelos y roto su sistema defensivo, mientras que los otrora orgullosos señores blancos deambulaban desconcertados y sus altivas esposas recorrían las calles vestidas con sacos y con los rostros cubiertos de ceniza.

Al final se supo que la conspiración no llegó a fraguar porque los indígenas consideraron que sin el apoyo de los numerosos esclavos negros era imposible triunfar. Por fortuna para españoles y criollos dicho apoyo nunca llegó, es más, la trama fue denunciada por un esclavo que, tras ser invitado a participar, la delató a su amo y éste fue con la información al virrey. El propio conde de Superunda tuvo muy clara la relación existente entre la

\footnotetext{
29 Pérez-Mallaína: Retrato de una ciudad... págs 346-347. Walker y Ramírez Castañeda: "Cuentas y cultura material..." págs. 657-696.

30 AGN, Cabildo, Causas Civiles, 103, cuaderno 2113. Éste fue el caso del artesano José de Barrios, un "moreno libre" que vivió varias décadas en una vivienda provisional en el centro de Lima.
} 
ruina de la capital y la frustrada rebelión de El Cercado. Así, en una carta enviada al monarca indicaba que para que los indígenas no tuvieran en el futuro tan "depravados pensamientos", había que volver a poner a la ciudad "en estado de darse a respetar" y que, por eso, había acelerado la reconstrucción del único símbolo del poder hispano que todavía se encontraba derribado: la catedral metropolitana. ${ }^{31}$

\section{Percepciones del desastre}

Al preguntarnos cómo interpretaron los limeños las causas de la tragedia, la respuesta es muy clara: la inmensa mayoría de la población la consideró un castigo divino por los pecados cometidos. Desde una perspectiva general la actitud de los ciudadanos en 1746 no parece distinta a la de los pobladores de la capital tras el otro gran seísmo que la destruyó en 1687 o a la que manifestaron los habitantes de Cuzco luego del tremendo movimiento telúrico de 1650. Como en aquellas otras épocas y lugares, las calles y plazas de Lima se llenaron de una histeria penitencial evidenciada mediante todo un espectáculo del más puro tremendismo barroco.

Así, las vías llenas de escombros fueron recorridas por procesiones que llegaron a juntar hasta 6.000 flagelantes, entre los que se contaron desde venerables frailes hasta doncellas y niños pequeños, todos los cuales se mortificaban duramente según sus fuerzas. Al mismo tiempo, en los púlpitos se produjeron verdaderos maratones de predicaciones, en los que distintos oradores sagrados se sucedían unos a otros pidiendo a los fieles su más sincero arrepentimiento. Hubo auténticos héroes de la prédica que llegaron a producir más de 70 sermones en sólo tres meses. A todo ello se sumó la existencia de profetas que indicaban que los castigos no habían hecho más que empezar y auguraban la destrucción total de la ciudad, junto con la aparición de videntes del pasado que comenzaron a recordar señales y avisos que no habían sido tomados en cuenta y que ahora se relacionaban con la destrucción originada por la cólera divina. ${ }^{32}$

31 AGI, Lima, 417. El conde de Superunda al rey, Lima, 14 de diciembre de 1750.

32 Tal vez la mejor descripción contemporánea de lo acontecido en 1746 puede verse en: Llano Zapata, José Eusebio: Carta o diario que escribe don José Eusebio de Llano y Zapata a su más venerado amigo y docto correspondiente el doctor don Ignacio Quiroga y Daza, canónigo de la santa Iglesia de Quito, en que con la mayor verdad y crítica más segura le da cuenta de todo lo acaecido en esta capital del Perú desde el viernes 28 de octubre, cuando experimentó su mayor ruina..., Imprenta de Zúñiga, Madrid, 1748. 
Dicha cólera actuaba, según creían los limeños, de manera muy irregular, pues en una sociedad basada en el principio del privilegio, todos los que se salvaron creían que Dios había hecho con ellos una particular excepción. Al mismo tiempo pensaban que el correctivo había sido piadoso, porque pese a su brutalidad, siempre podía haber resultado peor y un cronista de 1746 afirmó que era un auténtico milagro, y evidente prueba de misericordia, que se hubieran derrumbado 3.000 casas, pero sólo hubieran perecido un millar de personas. ${ }^{33}$ Finalmente, la traumática experiencia se consideraba desde todo punto de vista como muy provechosa, pues con estos avisos, aunque algunos perdiesen sus bienes, muchos más cambiarían sus malos hábitos y ganarían la vida eterna.

Aunque hemos indicado que la actitud general de la población no parece haber cambiado sustancialmente con respecto a la de un siglo antes, desde un punto de vista individual sí se pueden entrever algunas actitudes diferentes. Así, por ejemplo, ocurrió con los supremos gobernantes del Perú. Mientras el duque de la Palata, que presidía el virreinato en 1687, llegó a predicar desde el púlpito llamando al arrepentimiento general y presidió una procesión en la que todos los oidores de la Audiencia fueron con el rostro lleno de ceniza y un dogal al cuello, en 1746, don José Antonio Manso no lanzó ningún sermón y se limitó a acudir a las procesiones discretamente vestido de negro, algo que imitaron varios oidores de entonces. $^{34}$

Pero dejando de lado estas muestras particulares de continencia en la histeria penitencial desatada, hay que reconocer que la mayoría de los más ilustres personajes de la vida limeña, entre los que se contaron oidores, catedráticos o altos jefes militares, entendió el terremoto como un castigo y muchos de ellos lo aseveraron por escrito. El arzobispo Barroeta se contó, como puede sospecharse, entre éstos últimos y en ese sentido se permitió, incluso, especificar qué tipo de pecados habían sido los mayormente responsables: para él se trataba de la homosexualidad, un fenómeno que para el prelado era muy común en la ciudad y que la podía llevar a mayo-

33 Individual y verdadera relación de la extrema ruina que padeció la ciudad de los Reyes del reino del Perú con el horrible temblor de tierra acaecido en la noche del día 28 de octubre de $1746 . .$. Se trata de una descripción anónima atribuida al jesuita Pedro Lozano. Un ejemplar de este impreso se conserva en: AGI, Lima, 787.

34 BNM, 9375. Fray Domingo Álvarez de Toledo al padre general de la orden de San Francisco, Lima 29 de octubre de 1687. En esta carta se indica que el duque de la Palata "predicó mucho rato". 
res castigos, como les había ocurrido a otras comunidades pecadoras empezando por la mismísima Sodoma. ${ }^{35}$

Y para que se vea hasta qué punto este tipo de advertencias calaba en lo más profundo de los miedos sociales, baste decir que en 1756, cuando ya habían pasado varios años desde la destrucción provocada por el terremoto, volvió a cundir la alarma ante la posibilidad de que un nuevo castigo completase la obra vengadora de la divinidad. En noviembre de aquel año, un venerable y respetado fraile se subió al púlpito de la iglesia de San Francisco y en la misa dominical, a la que asistían el rector de la Universidad de San Marcos y varios inquisidores, anunció con toda solemnidad que, según las revelaciones efectuadas por una monja bajo secreto de confesión, Lima iba a ser destruida por la ira divina convertida en lanzas de ardiente fuego que caerían desde el cielo y arrasarían la capital y a sus pecadores habitantes.

Nadie pareció dudar de la verosimilitud de la predicción y la noticia se extendió con angustiosa celeridad por toda la ciudad, de tal manera que al lunes siguiente, el Cabildo Municipal en pleno se presentó ante el arzobispo para ofrecerse a realizar una procesión penitencial que calmase la justa ira de Dios. Todo ello prueba hasta qué punto, si no todos, al menos los más representativos de los patricios estaban atentos a cualquier cambio de humor que se detectase en los ámbitos celestiales y creyeron a pies juntillas las revelaciones de una monja mística, admitiendo la posibilidad de un nuevo castigo, esta vez en la modalidad de caída libre de lanzas de fuego. ${ }^{36}$

Ahora bien, ¿acaso no hubo entre los habitantes de Lima quienes defendiesen que la ruina de la ciudad pudo estar causada por fuerzas naturales? Desde luego que sí. En realidad todas las personas cultas conocían las viejas teorías clásicas que relacionaban los terremotos con los gases procedentes de las combustiones del interior de la tierra, los cuales, al no encontrar salida, daban lugar a los movimientos sísmicos. Con todo, el conocimiento de semejantes planteamientos no impedía una interpretación religiosa final. El propio José de Acosta, buen conocedor de la geografía peruana, ya había expuesto las explicaciones grecolatinas sobre estos fenómenos, pero consideraba que, como cualquier otra acción natural, los terre-

35 AGI, Lima, 985. Edicto del arzobispo don Pedro Antonio de Barroeta, Lima, 2 de diciembre de 1757 .

36 AGI, Lima, 807. Todo el expediente sobre las predicciones fue enviado a España con una carta del arzobispo Barroeta fechada en Lima el 28 de enero de 1757. 
motos no dejaban de responder a la voluntad de Dios, que los empleaba como "alguaciles de la justicia divina", es decir, usando el temor que producían como forma de garantizar el mantenimiento del orden religioso.

Es la misma idea que había defendido Bernabé Cobo en el siglo XVII, y que a mediados del XVIII sostenía José Eusebio de Llano Zapata, el máximo exponente de la ciencia criolla peruana y sucesor de Pedro Peralta Barnuevo. Llano Zapata, autor de una observación muy interesante sobre el terremoto de 1746, puso de manifiesto en ella su completo conocimiento de las más modernas teorías sobre los movimientos sísmicos y el vulcanismo, pero también terminó aceptando, como fervoroso católico que era, la tesis del castigo divino como explicación última de lo sucedido. ${ }^{37}$

En realidad, los documentos sólo hablan de tres personas que se atreviesen a defender en público que la catástrofe tenía causas exclusivamente naturales. El primero fue un marino de guerra nacido en España y jefe de las fuerzas navales del Perú: el marqués de Ovando. El segundo era un religioso, el padre Chaves, amigo del primero, y el tercero fue el oidor criollo y futuro gran representante de la ilustración hispana: don Pablo de Olavide, al que ya nos hemos referido. ${ }^{38}$

Ovando era un marino con amplia formación científica y pertenecía a la misma escuela de personajes tan destacados como Jorge Juan y Antonio de Ulloa. A pesar de ser también un hombre profundamente religioso, se sentía indignado al ver cómo muchos de sus convecinos malgastaban las pocas fuerzas que les habían quedado tras la catástrofe en realizar lo que para él eran inútiles penitencias. En especial le dolía ver las que practicaban unas monjas mercedarias, que tenían su convento al lado de su casa, y que él consideraba como un verdadero "santuario de ángeles".

Según contaba el marqués, cada vez que se producía una réplica del temblor (y hubo cerca de medio millar en los tres meses siguientes) las pobres monjas se tiraban al suelo y se pasaban la noche siguiente con los brazos en cruz pidiendo perdón por los pecados propios y ajenos. Apenado por tales sufrimientos quiso, a través del intermedio del padre Chaves, convencerlas de lo inútil de su actitud y, posiblemente, al hacerlo se le debió

37 Llano Zapata: Carta o diario..., pág. 30.

38 El sentir de estos pocos que se atrevieron a enfrentarse a la opinión mayoritaria puede verse en: Ovando, marqués de: Carta que escribió el marqués de Ovando a un amigo suyo sobre la inundación de Callao, terremotos y estragos causados por ellos en la ciudad de Lima. En: Odriozola, Manuel: Terremotos. Colección de las relaciones de los más notables que ha sufrido esta capital y que la han arruinado..., Tipografía de Aurelio Alfaro, Lima, 1863, págs. 47-69. 
escapar algún inevitable comentario irónico, pues él mismo relata que les aconsejó que en vez de quedarse en vela con los brazos abiertos, más les valdría agarrarse a las tablas de la cama, pues en caso de producirse el anunciado nuevo maremoto, al menos les podían servir de flotador.

Cuando semejantes recomendaciones llegaron a oídos de las autoridades religiosas, el marqués de Ovando tuvo que sufrir la vergüenza de verse reprendido en público. En efecto, el padre provincial de la Orden de San Francisco se permitió amonestarlo desde el púlpito en una misa a la que asistían las principales autoridades civiles y religiosas de la capital. Aunque Ovando tuvo en aquella ocasión el apoyo explícito de Pablo de Olavide, no quiso que aquel suceso le llevara a una ruptura con la ortodoxia, y acudió al visitador de la Inquisición en busca de consejo, ofreciéndole una retractación si así lo consideraba oportuno el Santo Oficio.

Podíamos preguntarnos si esta actitud de los limeños de considerar mayoritariamente el temblor como un castigo constituía una excepción o, por el contrario, respondía a lo que constituía la norma entre otras ciudades de su ámbito cultural sometidas a trances semejantes. Para establecer la comparación contamos con la proximidad en el tiempo del terrible seísmo que el primero de noviembre del año 1755 arrasó Lisboa y afectó seriamente a algunas ciudades españolas como Sevilla o Cádiz, sentido incluso en varios puntos fuera de la Península Ibérica.

La conclusión que se obtiene al estudiar las crónicas de la época es que, al menos dentro del mundo católico, la respuesta de los lisboetas fue muy parecida a la que tuvieron los limeños. Tanto en la capital portuguesa, como en Cádiz o Sevilla, se produjeron las mismas manifestaciones penitenciales y en esta última ciudad llegó a levantarse una columna de piedra dedicada al triunfo de la Virgen María sobre el mal, representado por el terremoto ${ }^{39}$ Este monumento, colocado al lado del Archivo General de Indias, sirve hoy a los investigadores que lo visitan como recuerdo de aquellos sucesos y la inscripción que posee en su base nos explica que el Cabildo de la Catedral agradecía a la intercesión de María el haberse salvado de la ira divina.

Es verdad que en España, como había ocurrido en el Perú, hubo una minoría de científicos que defendieron las causas exclusivamente naturales del fenómeno. Ésa fue la postura de Benito Jerónimo Feijoo, pero su argu-

39 Aguilar Piñal, Francisco: "Conmoción espiritual provocada en Sevilla por el terremoto de 1755”, Archivo Hispalense, Sevilla, 1973, págs. 37-53. 
mentación científica no le llevó tampoco a ninguna ruptura drástica con la ortodoxia. Realmente, el único intelectual destacado que utilizó el terremoto para plantear una visión heterodoxa del problema del mal en el mundo fue Voltaire. ${ }^{40}$

François-Marie Arouet constató la paradoja que podía suponer para la ideología religiosa católica el que una ciudad tan creyente y temerosa de Dios como Lisboa quedase totalmente arrasada. Ello le llevó a escribir un cuento, su famoso "Cándido", y un poema filosófico, que tuvieron como hilo conductor la destrucción de la capital portuguesa y en los que el autor se refirió a la ruina sufrida años antes por Lima. En ambas obras Voltaire retoma el viejo dilema del filósofo Epicuro que ya muchos siglos antes planteaba que si Dios no quería evitar el mal, no era bueno, y si no podía hacerlo, no era todopoderoso. Esta posición no fue compartida, ni siquiera por otras grandes figuras de la Ilustración. Juan Jacobo Rousseau no estuvo de acuerdo con imputar la responsabilidad de las muertes a la divinidad, y mantuvo con su colega una agria discusión defendiendo la postura de que era la codicia humana, levantando construcciones endebles en ciudades masificadas, la verdadera responsable de las muertes ocasionadas por los seísmos, que no producían ningún daño cuando tenían lugar en campo abierto.

¿En la Lima de mediados del siglo XVIII podían haberse expresado libremente las ideas del "Poema sobre la destrucción de Lisboa"? Desde luego que no. Pero tampoco en Francia y ni siquiera en Ginebra, en donde se encontraba exiliado Voltaire, se pudo hacer con total libertad. El filósofo francés tuvo que cambiar el final de su poema para no molestar al clero calvinista y conseguir, finalmente, publicarlo. Tras alterar algunos versos apareció una confianza final en la divina providencia, en lo que inicialmente era un angustiado canto de desesperanza. Es decir, si el marqués de Ovando estuvo dispuesto a retractarse presionado por el clero limeño, Voltaire, forzado por el ginebrino, tuvo que maquillar su inicial amargura con un trasparente y postizo barniz de esperanza.

Ahora bien, el terremoto de Lima no sólo fue percibido como un castigo divino que destrozaba sus edificios, sino como una mortal plaga que, a través de los nocivos vapores que se escapaban por las grietas abiertas en el suelo, era capaz de envenenar la tierra, dejándola estéril durante muchos

40 Villar, Alicia: Voltaire-Rousseau. En torno al mal y la desdicha, Alianza Editorial, Madrid, 1995 
años. Se trata de la construcción de un verdadero mito creado y reforzado tras los sucesos de 1746, aunque normalmente se le ha relacionado tan sólo con el otro gran seísmo que destruyó Lima en 1687.

En efecto, algunos años después de 1687 se produjo una gran crisis agrícola que acabó para siempre con la producción triguera de los valles cercanos a Lima. Gracias a la documentación, hasta hace muy poco desconocida, procedente del Archivo General de Indias de Sevilla, ha quedado demostrado que no hubo ninguna relación entre el terremoto y la esterilidad que más tarde sufrieron aquellas tierras ${ }^{41}$ La prueba más irrefutable al respecto consiste en comprobar que después de 1687 y hasta 1692 hubo varios años de magníficas cosechas de cereales en los valles de la costa central del Perú. Por todo ello, los limeños de fines del siglo XVII nunca establecieron ninguna relación entre el terremoto y la esterilidad de las tierras, que no empezó a notarse hasta los primeros años de la década del '90. Lo que sí se estableció por entonces fue un lucrativo comercio de trigo chileno hacia el Perú, que enriqueció a los terratenientes chilenos, pero también a los comerciantes, transportistas y dueños de barcos que residían en Lima.

Estos últimos, que a mediados del siglo XVIII seguían interesados en el mantenimiento de este comercio cerealista entre Chile y Perú, fueron los que inventaron la calumnia geográfico-agrícola de que los terremotos envenenaban la tierra. Algunos afirmaron que lo mismo que había ocurrido tras el terremoto de 1687 volvería suceder tras el de 1746, pues los campos habían quedado infectados y el trigo producido en el Perú podía resultar perjudicial para la salud. De nada sirvió que algunas destacadas autoridades del virreinato, como el oidor de la Audiencia don Pedro José Bravo de Lagunas, escribiesen un notable tratado a favor de la agricultura local. El daño estaba hecho, y los navieros y transportistas peruanos impusieron sus intereses ante los hacendados, utilizando armas tanto económicas como las pseudocientíficas de la nociva influencia de los terremotos sobre la productividad del terreno. ${ }^{42}$

Ahora bien, lo realmente curioso es que este mito geográfico haya influido en la creación de otro mito, esta vez de carácter historiográfico.

41 Pérez-Mallaína Bueno, Pablo E.: "La fabricación de un mito: el terremoto de 1687 y la ruina de los cultivos de trigo en el Perú”, Anuario de Estudios Americanos, LVII-1, Sevilla, 2000, págs. 69-88.

42 Bravo de Lagunas y Castilla, Pedro José: Voto consultivo que ofrece al excelentísimo señor don José Antonio Manso de Velasco... el doctor don Pedro José Bravo de Lagunas y Castilla..., Lima, 1761. 
Nos referimos a la teoría que incluye entre las causas de la decadencia del Perú a fines del XVII la existencia de una crisis agrícola desatada por los terremotos. El hecho de que a lo largo del siglo XVIII el virreinato peruano se viera reemplazado por el de México como la gran joya de las posesiones españolas en América es un factor muy complejo y los historiadores solemos acumular razones para explicarlo: el agotamiento de las minas y de la mano de obra sometida a la mita, los cambios geoestratégicos y de las rutas marítimas, etc. Añadir a ello la decadencia agrícola consecuencia de los terremotos parece, a primera vista, una forma de completar el cuadro explicativo. Sin embargo, un estudio sistemático de las muchas informaciones que salieron a la luz durante estas grandes crisis nos indica que en el complejo drama de la decadencia del Perú colonial los terremotos tuvieron, como mucho, un papel de extras o figurantes, pero nunca de protagonistas principales. 